\title{
Isolated focal cortical dysplasia
}

INSERM

\section{Source}

INSERM. (1999). Orphanet: an online rare disease and orphan drug data base. Isolated focal cortical dysplasia. ORPHA:65683

Isolated focal cortical dysplasia is a rare, genetic, non-syndromic cerebral malformation due to abnormal neuronal migration disorder characterized by variable-sized, focalized malformations located in any part(s) of the cerebral cortex, which manifests with drugresistant epilepsy (usually leading to intellectual disability) and behavioral disturbances. Abnormal MRI findings (e.g. abnormal white and/or grey matter signal, blurred graywhite matter junction, localized volume loss, cortical thickening, abnormal gyral pattern, abnormal hippocampus) and variable histopathologic patterns are associated. 